\title{
ASSOCIATION OF PRE-HYPERTENSION WITH BLOOD GROUPS IN YOUNG POPULATION.
}

\author{
1. MBBS, M.Phil \\ Assistant Professor \\ Department of Physiology \\ Aziz Fatima Medical and \\ Dental College, Faisalabad. \\ 2. MBBS, M.Phil \\ Associate Professor \\ Department of Physiology \\ Aziz Fatima Medical College, \\ Faisalabad. \\ 3. Final year Student (BS BioTech) \\ Foreman Christian College LHR \\ (FC College). \\ 4. FCPS \\ Senior Registrar \\ DHQ, Faisalabad. \\ 5. MBBS \\ Senior Demonstrator \\ Department of Physiology \\ Aziz Fatimah Hospital Faisalabad. \\ Correspondence Address: \\ Dr. Shireen Jawed \\ Associate Professor \\ Department of Physiology \\ Aziz Fatima Medical College, \\ Faisalabad. \\ drshireenjawed@gmail.com \\ Article received on: \\ 31/10/2018 \\ Accepted for publication: \\ 09/03/2019
}

\begin{abstract}
Benash Altaf', Shireen Jawed ${ }^{2}$, Fakiha Behram ${ }^{3}$, Zeeshan Ali Khan ${ }^{4}$, Shakeela Naz ${ }^{5}$
\end{abstract}
\begin{abstract}
Objectives: Pakistan has highest mortality rate due to hypertension and its complications. Hypertension is a squealed of Pre- hypertension which is believed to start at adolescent and continue to adulthood. Association of blood group with hypertension is evident but still hypothesized. This study aims to find the frequency of prehypertension and its association with blood group. Study Design: Cross sectional study. Setting: Aziz Fatimah Medical and Dental College, Faisalabad. Period: 15 March to 15 Sep 2018. Material and Methods: It was comprised of in comprised of 100 MBBS students. Demographic data including age, weight, height, waist and hip circumference, and BMI was determined. Blood group was determined with help of conventional slide method. Blood pressure was measured by auscultatory method. Data was analyzed by using SPSS 21. Continuous variables are given in mean and standard deviation. Categorical data was given in frequency and percentages. $P$ value $\leq 0.05$ is taken as significant. Results: Out of 100 participants most common blood group was group 'O' (43\%) followed by B (35\%) and AB (13\%) and A (9\%).36\% of total population was pre-hypertensive and $64 \%$ were normotensive. Prehypertension is most commonly found in blood group ' $A$ ' (77\%) followed by blood group 'O' (46.5\%). Significant difference was found in means of SBP $\left(p\right.$ value $=0.001^{*}$ ) and DBP ( $p$ value $=0.000^{*}$ ) among the various blood groups. Conclusion: Most common blood group in studied population was 'O' although hypertension was most commonly observed in blood group A followed by 'O'.
\end{abstract}

Key words: Blood Groups O, Blood Group A, Hypertension, Prehypertension.

Article Citation: Altaf B, Jawed S, Behram F, Khan ZA, Naz S. Association of Prehypertension with blood groups in young population. Professional Med $\mathrm{J}$ 2019; 26(11):1820-1824. DOI: 10.29309/TPMJ/2019.26.11.469

\section{INTRODUCTION}

Hypertension is a cause for concern in today's health care system on a global scale. ${ }^{1}$ The prevalence of hypertension in Pakistani young adults over age of 25 years is estimated and $28 \%$ and this rate is continuously increasing since $1990 .{ }^{1}$ Studies are available showing that hypertension is usually preceded by prehypertension which start since childhood adolescence and continue into adulthood. Most probably this trend is increasing in this age group because of sedentary and unhealthy lifestyle. ${ }^{1,2}$ It is evident from previous studies risk for prehypertension in young undergraduate student of age 20-30 years were higher than the general youth population. Prevalence of prehypertension in young adults of Indo sub continental area was $45 \%$ to 55 which is still rising. ${ }^{2}$ Prehypertension and Hypertension in young adulthood increases the risk of cardiovascular ailments in them. It is evident that the less than half $(49 \%)$ of the young diagnosed hypertensive adults are taking treatment and rest of them are non-compliant to take medication because of non-serious attitude towards their health. ${ }^{3}$ Strong evidences are also available showing that young hypertensive generation on treatment has poor control as compared to middle-aged and older adults. ${ }^{3}$ Due to decrease trends for routine medical check-up, most of the young adults remain undiagnosed and are susceptible to develop cardiovascular diseases.

Pre hypertension was based primarily on slight raised levels of blood pressure (i.e. systolic blood pressure between $120-139 \mathrm{mmHg}$ for and 
$80-89 \mathrm{mmHg}$ for diastolic) is used to identify a group of children/adolescents for whom targeted preventive efforts would be most beneficial. This review examines the knowledge that has been gained regarding the epidemiology and risk associated with prehypertension in adolescents. There is emergent need of early screening of young adults for pre hypertension since its inception and highlight future challenges for understanding and preventing the development of hypertension in this young population. For this purpose the recognition of risk factors are required. Earlier researches have documented the association of high blood pressure and blood groups. ${ }^{4}$ This study can help in providing information about certain blood groups that are associated with raised BP (pre-hypertention). Hence subjects with these blood group who are at risk of developing full blown condition could remain vigilant for themselves with proper medical follow-ups so it could be prevented in time.

Clinically, the most important system is the $A B O$ system comprised of $A, A B, B$ and $O$ blood groups. It was discovered by Karl Landsteiner in 1901. Later on, another rhesus (Rh) blood group was identified by the same scientist along with Weiner in 1940.4,5 The A and B antigens are oligosaccharide, expressed on erythrocyte surface, platelets, vascular endothelium and tissue cells. ${ }^{6}$ The regulation of $\mathrm{ABO}$ blood group system is under control of $\mathrm{ABO}$ gene expression. ${ }^{7}$ Genes for $A B O$ antigens and $\mathrm{Rh}$ antigen are located on chromosome number 9 and 1, respectively.,8 Several epidemiological studies have reported that populations of different geological areas have varying distribution of $\mathrm{ABO}$ blood groups. ${ }^{9}$ Research carried out specifically in Punjab shows a higher prevalence of blood group $B$ in this region. 9,10 Since the discovery of the $A B O$ system, it's significance regarding evolution, paternity, finger printing, inheritance pattern, legal medicine, blood transfusion and genetic study, as predictor of national suicide rate, are all well documented by past researches. ${ }^{5,10}$

The study of blood group systems is significant in the advancement of modern medicine as they are closely associated with several diseases. ${ }^{11}$ Blood group A has been reported to be associated with cervical cancer by several studies. ${ }^{10}$ Due to genetic factors, people with blood group B are more susceptible to develop diabetes type-2. ${ }^{12}$ Past researches have validated the association of blood group B with obesity subsequently leading to hypertension. ${ }^{13}$

Concerning association of blood groups and hypertension many studies are conducted internationally, however controversial results were reported and this issue is still debate upon. Exploration of association between blood groups and blood pressure is a fundamental requirement to identify the population at risk for hypertension. A positive co-relation with blood groups would exhibit a rise in susceptibility to prehypertension which still needs further extensive research to provide validation. This study was designed to find frequency of pre- hypertension among the young adults and to explore its association with blood groups for early identification of population at risk. The life threatening consequences of hypertension can only be overcome by taking preventative measures and modifying the life style.

\section{MATERIAL METHOD}

Current cross sectional study was carried on 100 students at Aziz Fatimah medical and dental college, Faisalabad. 100 students were enrolled in this study after ethical approval. Informed written consent was taken from every student and privacy was assured. Demographic evidences and history of all the subjects were taken on a pre-designed proforma. After doing physical examination, blood pressure was measured by mercury sphygmomanometer with auscultator method by exposing the arm and then applying the cuff $2 \mathrm{~cm}$ above the popliteal fossa. Total of 3 blood pressure $(\mathrm{BP})$ readings were taken. Systolic and diastolic BP were taken at the first appearance of sound (phase I) and the disappearance of sound (phase V) called as Korotkoff sounds. After relaxing and calming the student, 3 readings, each reading with the interval of 1 minute were taken in the sitting position, then average of these three readings were entered in the data. ${ }^{14}$ Zero error and parallax was avoided before recoding the BP. ${ }^{15}$ Cut off 
point for systolic blood pressure (SBP) is taken as $120-139 \mathrm{mmHg}$ or diastolic blood pressure (DBP) was $80-89 \mathrm{mmHg}$ for prehypertension. SBP $\geq 140 \mathrm{mmHg}$ and/or DBP $\geq 90 \mathrm{mmHg}$ are considered as hypertension Normotensives are taken as $\mathrm{BP}$ values $\leq 120 / \leq 80 \mathrm{~mm} \mathrm{Hg}$ as per Joint National committee criteria (JNC). Blood group was determined in physiology lab of Aziz Fatimah medical and dental college with the help of antisera A,B and Anti Rh factor.

\section{RESULTS}

This Study included 100 students (65 male 35 female) from Aziz Fatimah medical and Dental College with Mean \pm SD age of $23.7 \pm 1.03$. Descriptive of study population is presented in Table-l. Distribution of blood groups of the study population is shown in Figure-1. It is indicating that most common blood group found in our studied population is " $O$ ' followed by $B, A B$ and A.

Figure- 2 is indicating that $36 \%$ of total population

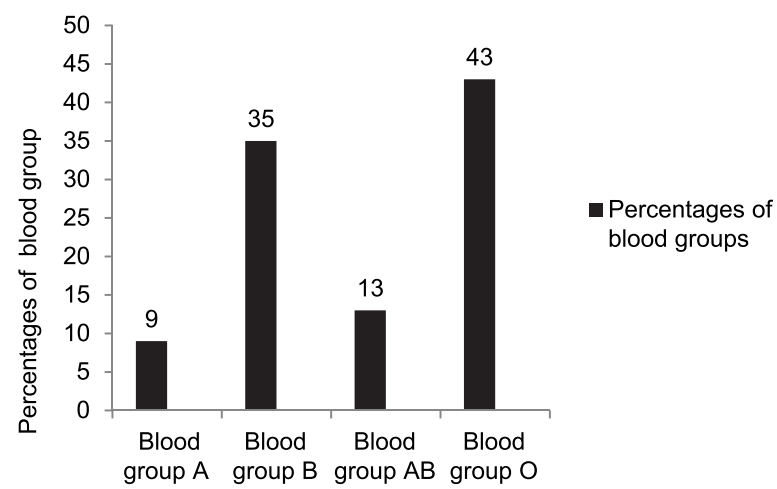

Figure-1. Distribution of blood groups in study subjects

was pre-hypertensiveand 64\% werenormotensive. Prehypertension is most commonly found in blood group 'A' (77\%) followed by blood group 'O' (46.5\%) (Table-II). Significant difference was found in means of SBP ( $p$ value $\left.=0.001^{\star}\right)$. and DBP $\left(p\right.$ value $=0.000^{*}$ ) among the various blood groups.

\begin{tabular}{|l|c|c|}
\hline & $\begin{array}{c}\text { Mean } \\
\mathbf{N = 1 0 0}\end{array}$ & $\begin{array}{c}\text { Standard } \\
\text { Deviation }\end{array}$ \\
\hline Age (year) & 23 & 1.038 \\
\hline Height $(\mathrm{cm})$ & 1.68 & 0.094 \\
\hline Weight(kg) & 67.8 & 14.7 \\
\hline Waist $(\mathrm{cm})$ & 32.7 & 4.18 \\
\hline Hip(cm) & 37.6 & 3.65 \\
\hline BMI $\left(\mathrm{kg} / \mathrm{m}^{2}\right)$ & 24.02 & 3.143 \\
\hline SBP $(\mathrm{mmhg})$ & 119 & 11.66 \\
\hline DBP $(\mathrm{mmhg})$ & 80.8 & 9.0 \\
\hline
\end{tabular}

Table-I. Baseline characteristics of study population

SBP $=$ Systolic blood pressure, $\mathrm{DBP}=$ Diastolic blood pressure $\mathrm{BMI}=$ body mass Index

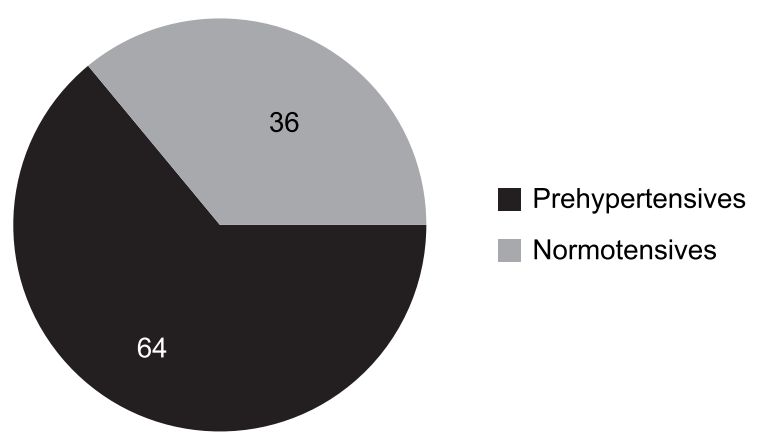

Figure-2. Percentages of prehypertension in study subjects

\begin{tabular}{|l|c|c|c|}
\hline \multirow{2}{*}{ ABO Blood Groups } & Systolic Blood Pressure & Diastolic Blood Pressure & Frequency of Prehypertension \\
\hline A $(n=9)$ & Mean \pm SD & Mean \pm SD & N $\%)$ \\
\hline$B(n=35)$ & $126 \pm 5.34$ & $87 \pm 6.61$ & $7(77.8)$ \\
\hline$A B(n=13)$ & $117 \pm 12.7$ & $77 \pm 9.72$ & $7(20)$ \\
\hline O $(n=43)$ & $116 \pm 10.3$ & $80 \pm 7.3$ & $2(15.4)$ \\
\hline P value & $120 \pm 11.7$ & $82 \pm 8.3$ & $20(46.5)$ \\
\hline
\end{tabular}

Table-II. Comparison of blood pressure among blood groups

Means are compared by independent sample t-test.

$\mathrm{X}^{2}$ test was used to compare proportions.

$P$ value $\leq 0.05$ is taken as significant 


\section{DISCUSSION}

$\mathrm{ABO}$ blood group system and $\mathrm{Rh}$ system is seeking attention in recent era. Hypertension and other diseases are now been linked with specific blood groups. Etemadi A, et al. and other researches showed relationship of several vascular diseases and other life threatening conditions like carcinoma cervix to blood group other than 'O'.11,16,17 Diverse types of blood groups are distributed globally with predominance of one blood group in various regions. Diversity of blood groups reflects the genetic makeup of different ethnicity and races. Blood group $\mathrm{O}$ was most commonly found blood group in our studied subjects, subsequently $B, A B$ and then $A$. These findings are in contrary to the research conducted in Lahore on vast number of blood donors who found a population dominating in blood group B. ${ }^{18}$ However different distribution and diversity for specific blood group is found in Sindh, KPK and northern zones of Pakistan when we compare it with upper Punjab. 5,7,9,10,19 However concerning blood group $A B$, all the researches showed the common finding indicating that it's the least common one. But in our studied population the least commonly found blood group was A. ${ }^{19}$ Our results reveals $36 \%$ of total study population was found to have prehypertension. Significantly different values for SBP $(P=0.000)$ and DBP $(P=0.001)$ was observed among the various blood groups. Blood pressure was higher in subjects with blood group A then subjects with other blood groups. $77 \%$ of the of the subjects with blood group $A$ have prehypertension and $44 \%$ of subjects with $O$ blood group was prehypertensive. Greater number of the subjects with these two blood groups in our studied population has prehypertension as compared to other blood groups these results are in concordance with results of Jasim. ${ }^{20}$ Contradictory to our results, Supratik B etal documented higher prevalence of prehypertension and hypertension in blood group $\mathrm{B}^{13}$

There is emergent need of future researches concerning diversity of blood group with its association for developing life threatening conditions like hypertension and associated cardiovascular diseases. So it must be analyzed on broader scale for better understanding of mechanism of prehypertension for recognizing population at risk to prevent HTN and associated complications.

\section{CONCLUSION}

Majority of the studied population has blood group ' $O$ '. Pre-hypertension was most commonly found in blood group ' $A$ ' followed by ' $O$ '.

Copyright $\odot 09$ March, 2019.

\section{REFERENCES}

1. Aahmad L, Andrew J. Semotiuk, etal Anti-hypertensive plants of rural Pakistan: Current use and future potential. Journal of complementary medicine research, 2018; 7(2): 138-153.

2. Peltze K, Pengpid S, etal. Prehypertension and psychosocial risk factors among university students in ASEAN countries. BMC Cardiovascular Disorders 2017. 17:230 DOI 10.1186/s12872-017-0666-3.

3. Johnson $\mathrm{H}$ M et al.: Antihypertensive medication initiation among young adults. J Gen Intern Med. 2014 L:29(5):723-31. DOI: 10.1007/s11606-014-2790-4.

4. Sana Ullah, Ahmad T. Distribution of $\mathbf{A B O}$ and $\mathbf{R h}$ (D) blood groups in the population of district DIR LOWER, Khyber Pakhtunkhwa Pakistan. World Applied Sci J. 2015; 33: 123-35.

5. Tesfaye K, Petros Y, Andargie M. Frequency distribution of $A B O$ and $R h(D)$ blood group alleles in Silte Zone, Ethiopia. Egypt J Med Human Gen. 2015; 16: 71-6.

6. Maatoghi JT, Paridar M, Shoushtari MM, Kiani B, Nori B, Shahjahani M, et al. Distribution of ABO blood groups and rhesus factor in a large scale study of different cities and ethnicities in Khuzestan province, Iran. Egypt J Med Human Gen. 2016; 17: 105-9.

7. Alamgeer, Noor N, Khan H, Akram S. Study about health consciousness and awareness of blood groups in the selected population of University of Sargodha. Pak Pharmaonline. 2011; 2:1119-25.

8. Shaik YA, Alhawary AS, Shbair AS, Hamouda BB. Frequency of $A B O$ and $R h D$ blood groups in five governorates in Gaza-Strip. Pak J Med Sci. 2007; 23: 924-27.

9. Alam M. ABO and Rhesus blood groups in potential blood donors at Skardu (Northern Areas). Pak J Pathol. 2005; 16: 94-7. 
10. Pasha AK, Hashir MM, Khawar S. Frequency of ABO blood groups among medical students. J Surg Pak. 2009; 14: 15-20.

11. Sukalingam K, Ganesan K. Rhesus blood groups associated with risk to obesity and diabetes mellitus: A report on punjabi population in Selangor, Malaysia. Int J Intg Med Sci. 2015; 2: 105-09.

12. Chuemere AN, Olorunfemi OJ, Nwogu JU, Mmom OF, Agbai EO, Vurey V V. Correlation between blood group, hypertension, obesity, diabetes, and combination of prehypertension and pre- diabetes in school aged children and adolescents in port Harcourt. J Dent Med Sci. 2015; 14: 83-9.

13. Supratik B, Ganaraja B, Bhat R. Correlation between the blood groups, BMI and prehypertension among medical students. J Chinese Clin Med. 2010; 5: 78-82.

14. Smith L. New AHA recommendations for blood pressure measurement. Am Fam Phys. 2005; 72: 1391-8.

15. Whelton PK, Carey RM, Aronow WS, etal. 2017 ACC/ AHA/AAPA/ABC/ACPM/AGS/APhA/ASH/ASPC/NMA/ $P C N A$ Guideline for the prevention, detection, evaluation, and management of high blood pressure in adults: a report of the American college of cardiology/American heart association task force on clinical practice guidelines. J Am Coll Cardiol 2017; 13.
16. Etemadi A, Kamangar F, Islami F, Poustchi H, Pourshams A, Brennan P, Boffetta P, Malekzadeh R, Dawsey SM, Abnet $C C$, Emadi $A$. Mortality and cancer in relation to $A B O$ blood group phenotypes in the Golestan Cohort Study. BMC medicine. 2015 Dec;13(1):8.

17. Pasha AK, Hashir MM, Khawar S. Frequency of ABO blood groups among medical students. J Surg Pak. 2009; 14: 15-20.

18. Khan MU, Bashir MW, Rehman R, Kiani RA. Frequency of $A B O$ andRh (D) blood groups among blood donors in Lahore, Pakistan. Inter J Adv Biol Biomed Res. 2014; 29: 597-600.

19. Kanwal S, Qureshi HJ, Aslam MS, Masood S. Frequency of $\mathrm{ABO}$ and $\mathrm{Rh}$ blood groups in students of Akhtar Saeed Medical and Dental College, Lahore. Pak J Physiol. 2016; 12: 29-30.

20. Jassim WE. Association of ABO blood group in Iraqis with hypercholesterolaemia, hypertension and diabetes mellitus. East Mediterr Health J. 2012; 18: 888-91.

\section{AUTHORSHIP AND CONTRIBUTION DECLARATION}

\begin{tabular}{|c|l|l|}
\hline Sr. \# & Author(s) Full Name & \multicolumn{1}{|c|}{ Contribution to the paper } \\
\hline 1 & Benash Altaf & $\begin{array}{l}\text { Contributed to study design, Wrote } \\
\text { the manuscript and reviewed } \\
\text { references. She is the guarantor } \\
\text { of this work and as suck, had full } \\
\text { access to all the data in the study } \\
\text { and takes responsibility for this } \\
\text { integrity of the data and the accuracy } \\
\text { of the data analysis. } \\
\text { Contributed to data analysis, } \\
\text { interpretation, editing and formatting } \\
\text { the manuscript. Reviewed and } \\
\text { approved the manuscript. } \\
\text { Contributed to study design, helped } \\
\text { in manuscript writing and reviewed it. } \\
\text { Contributed to review the article and } \\
\text { approved it. } \\
\text { Contributed to acquisition of data. } \\
\text { Revising it critically for important } \\
\text { intellectual content. }\end{array}$ \\
\hline 5 & Shireen Jawed & Fakiha Behram
\end{tabular}

